\title{
CONFERENCE PHOTOGRAPHS
}




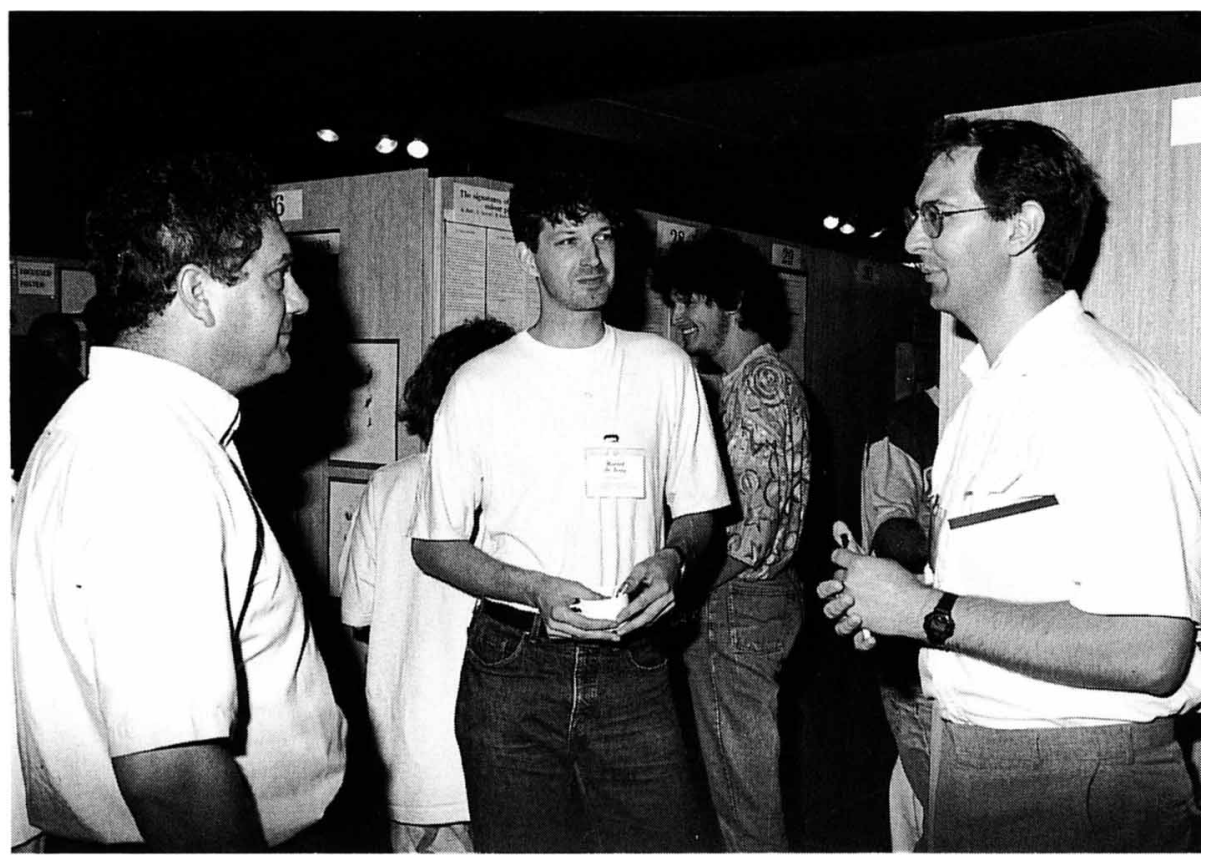

Rob Kennicutt, Roelof de Jong and Guy Worthey

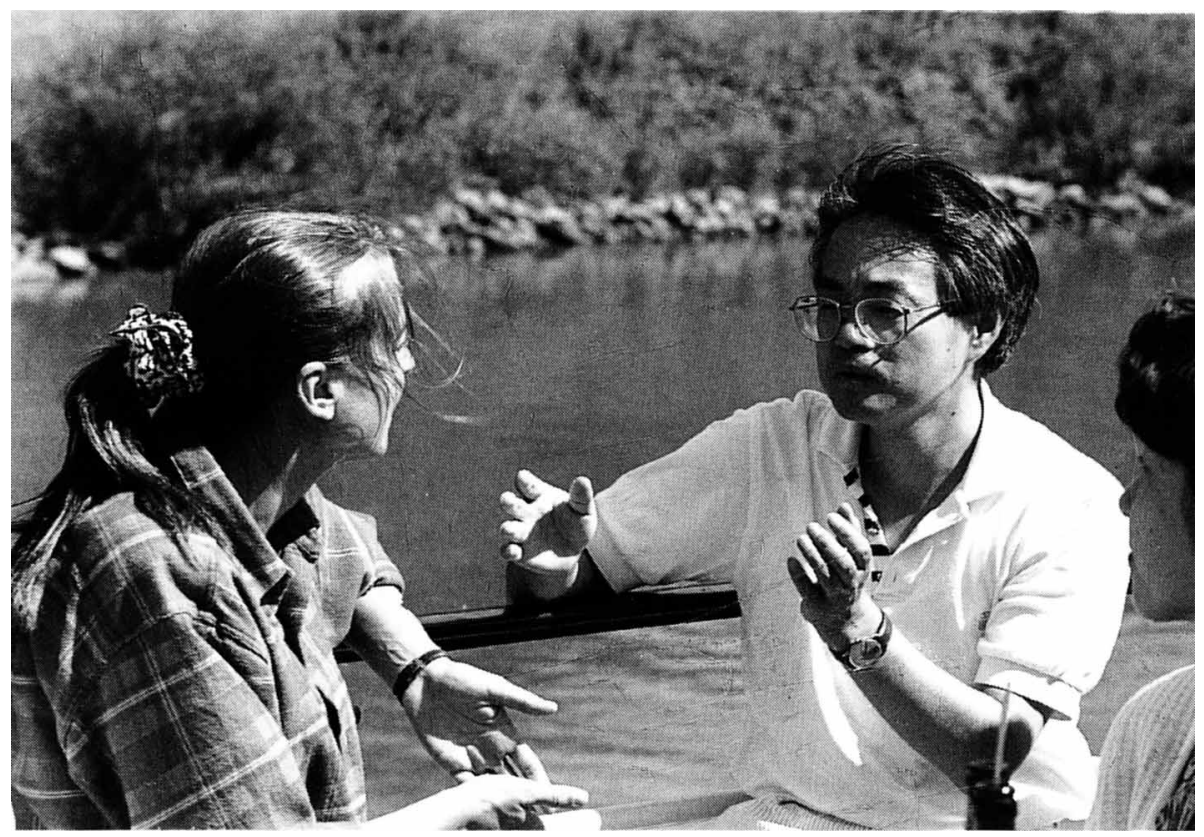

Bianca Poggianti and Nobuo Arimoto 


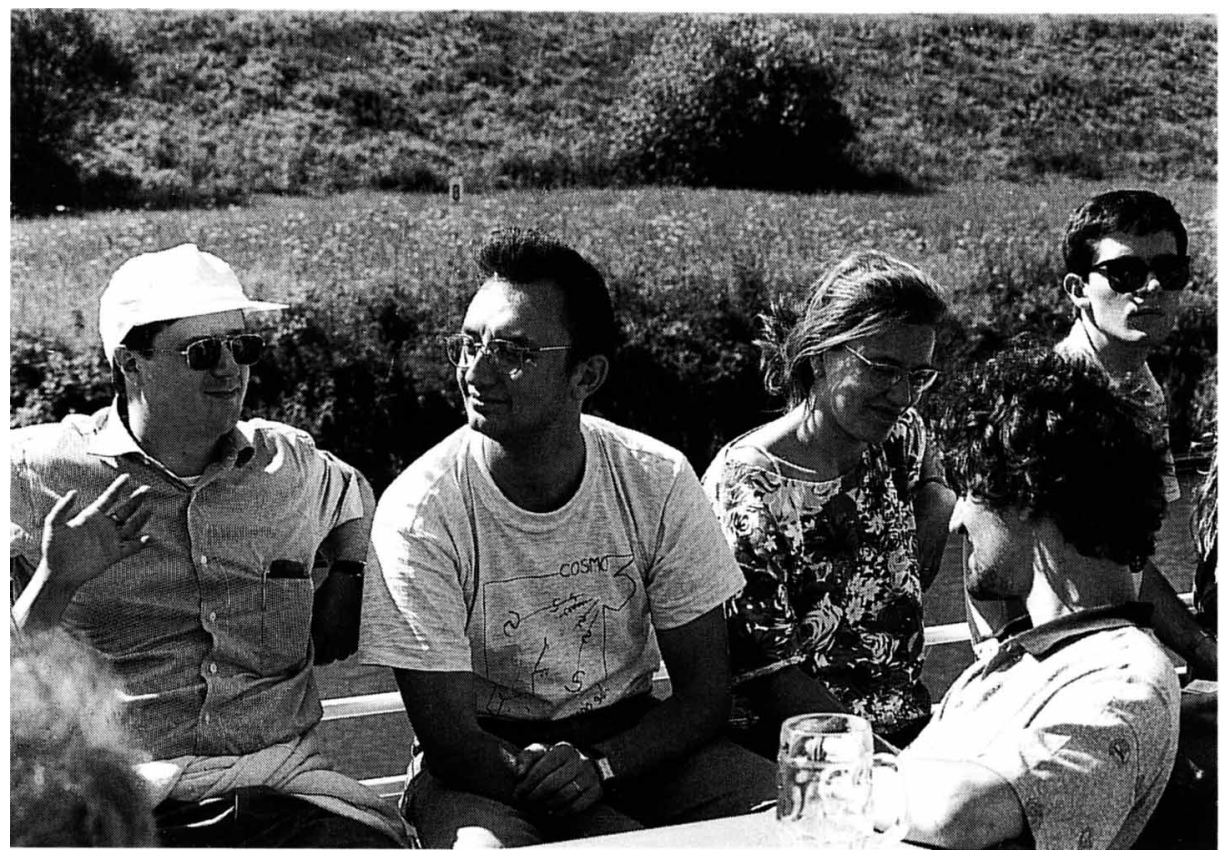

Mauro d'Onofrio, Luca Ciotti, Silvia Pellegrini and Nicola Caon

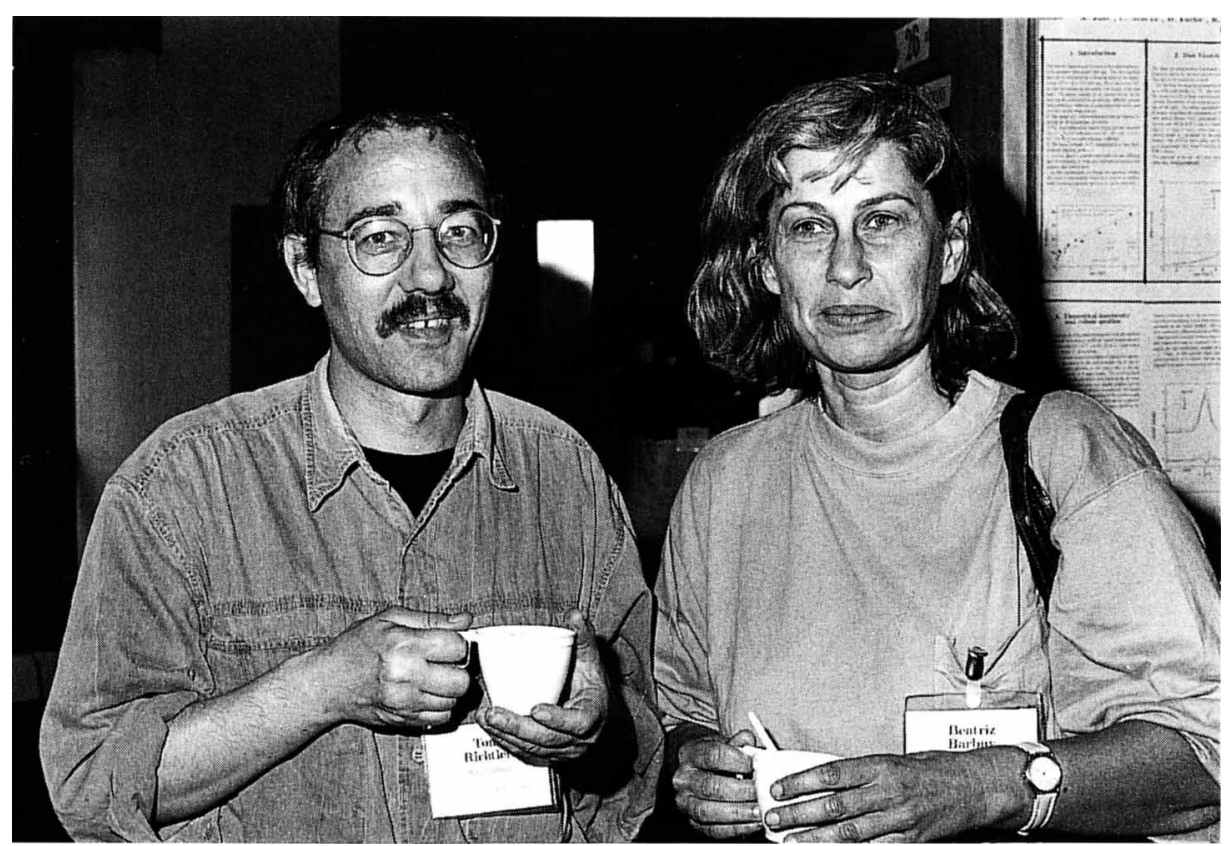

Tom Richtler and Beatriz Barbuy 


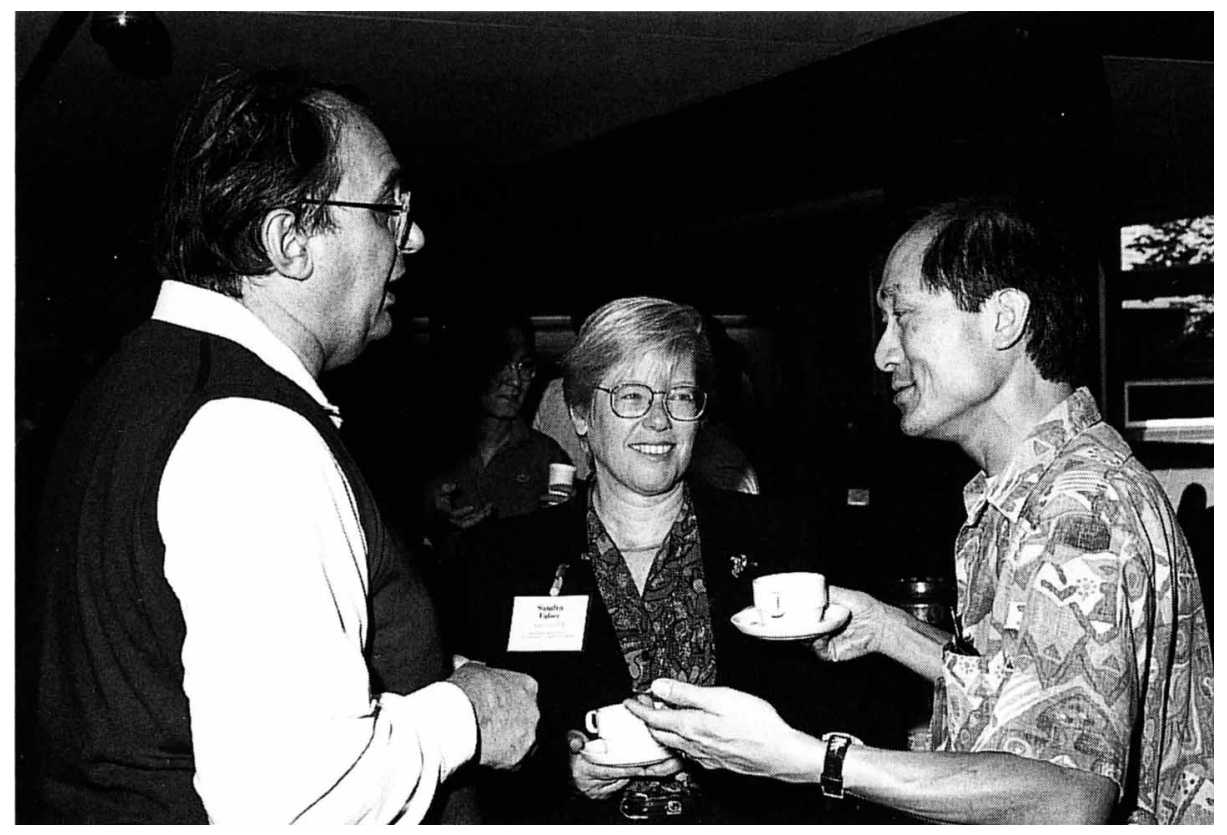

John Kormendy, Sandy Faber and David Koo

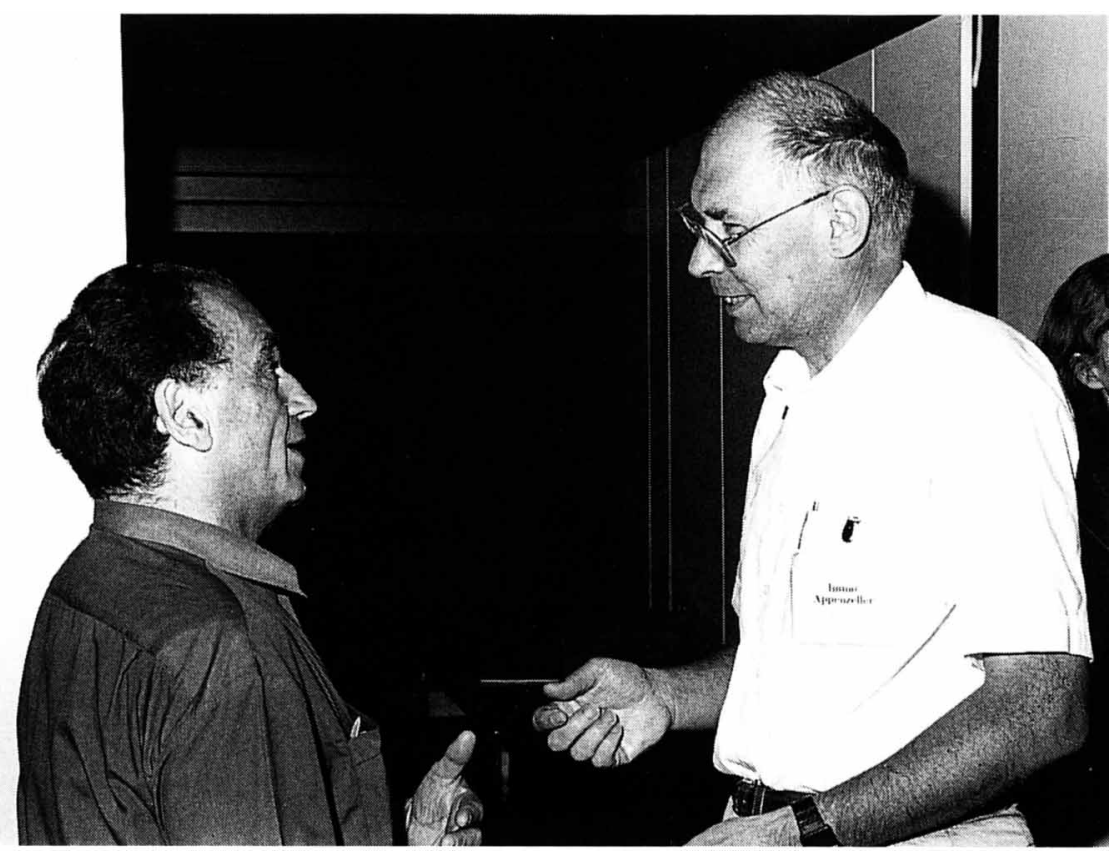

Ed Khachikian and Immo Appenzeller 




In the castle

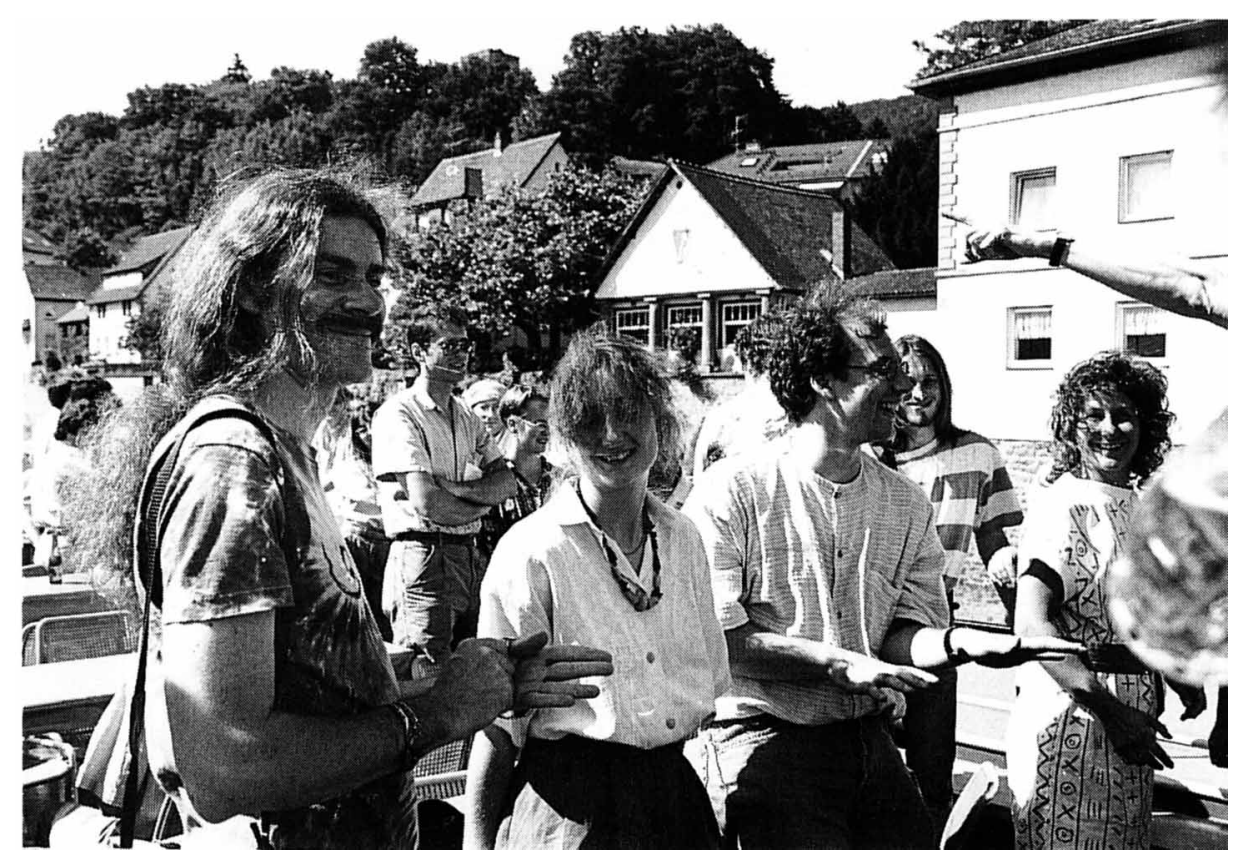

On the boat 


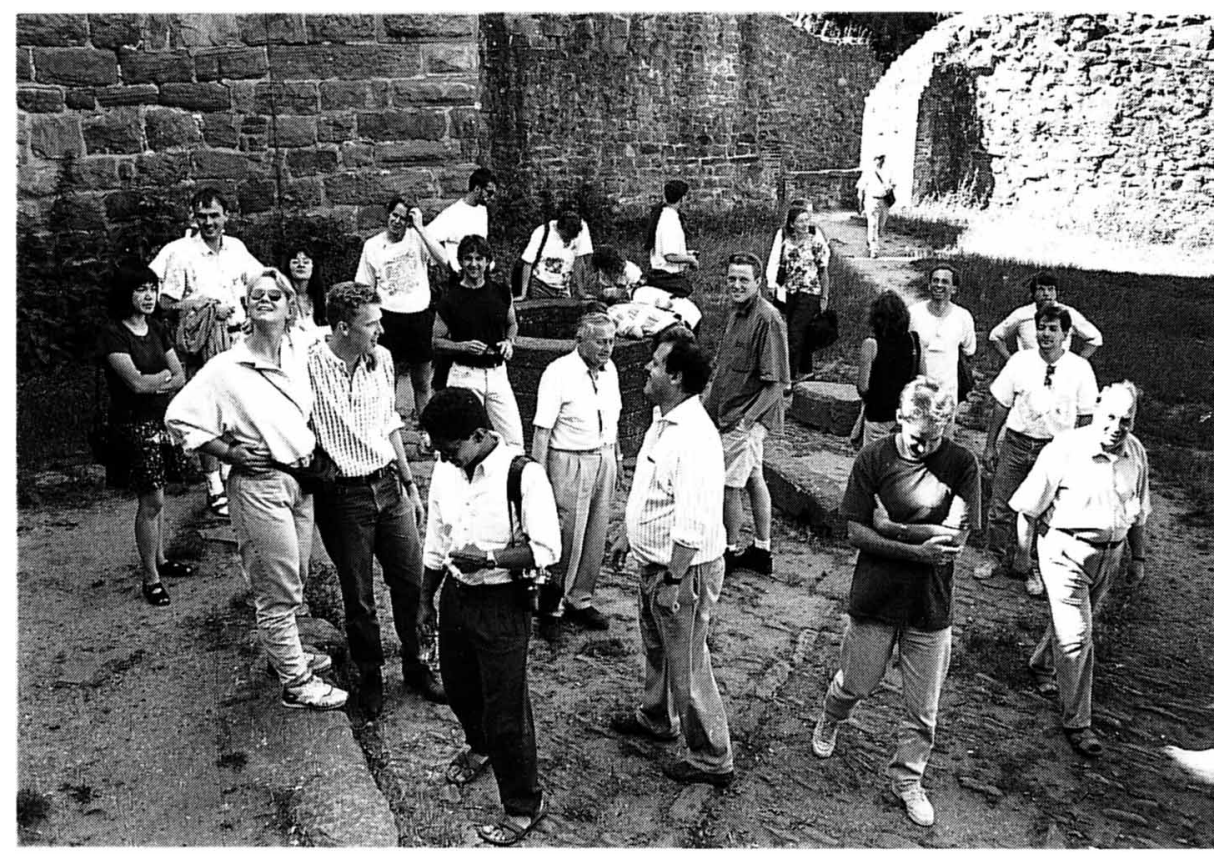

In the castle

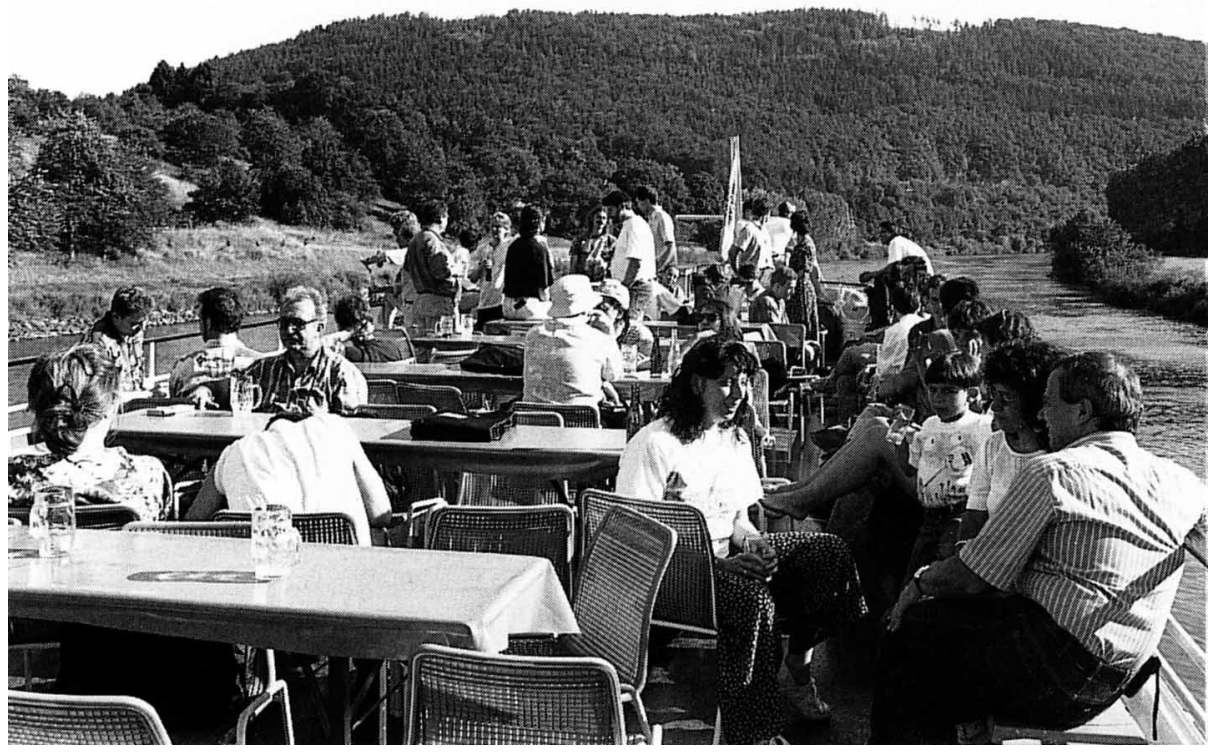

On the boat 


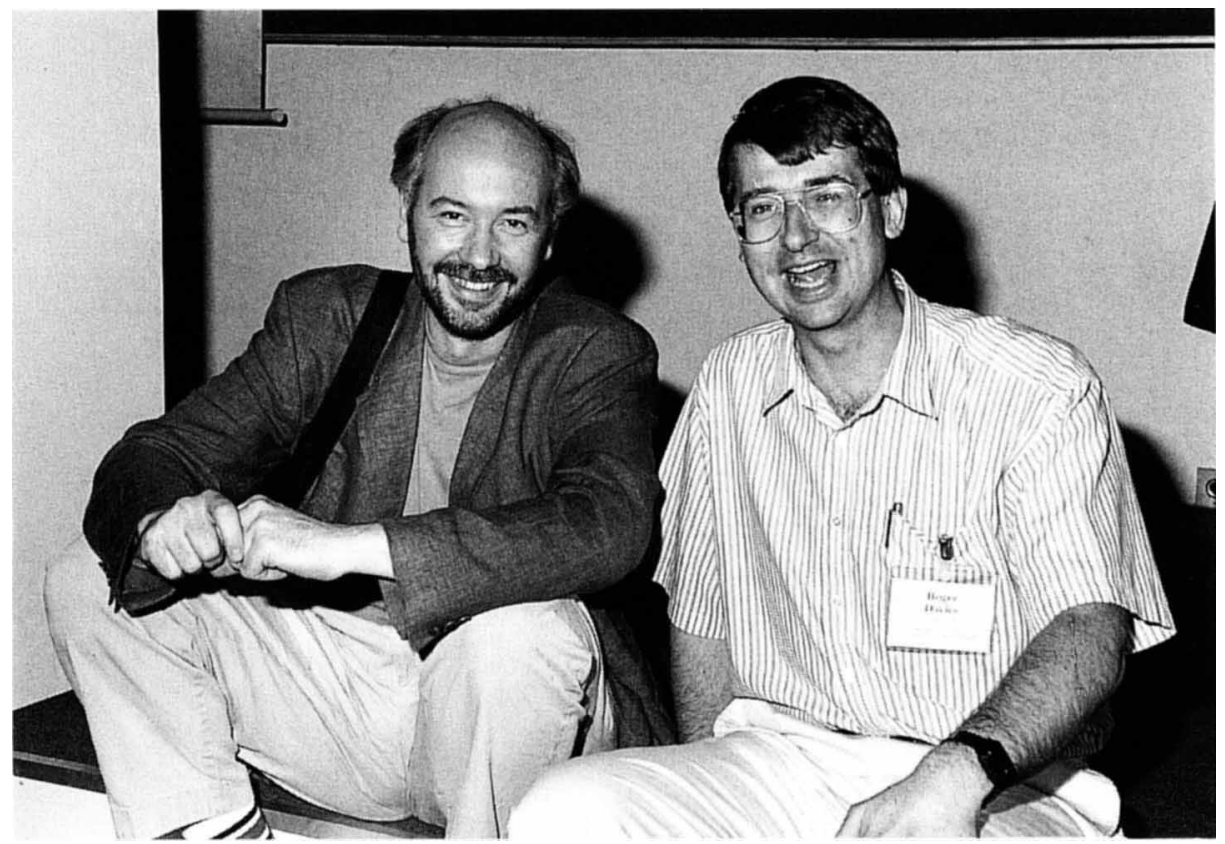

Ralf Bender and Roger Davies

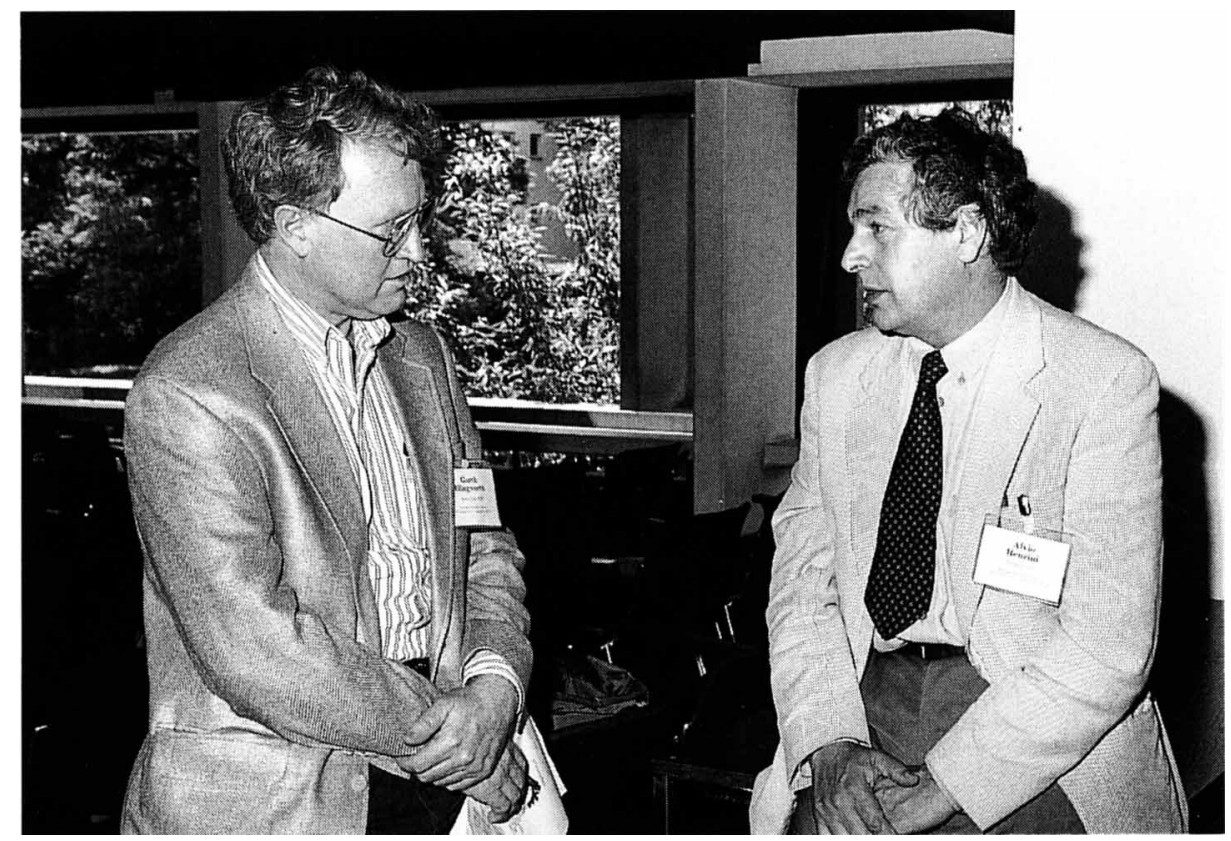

Garth Illingworth and Alvio Renzini 


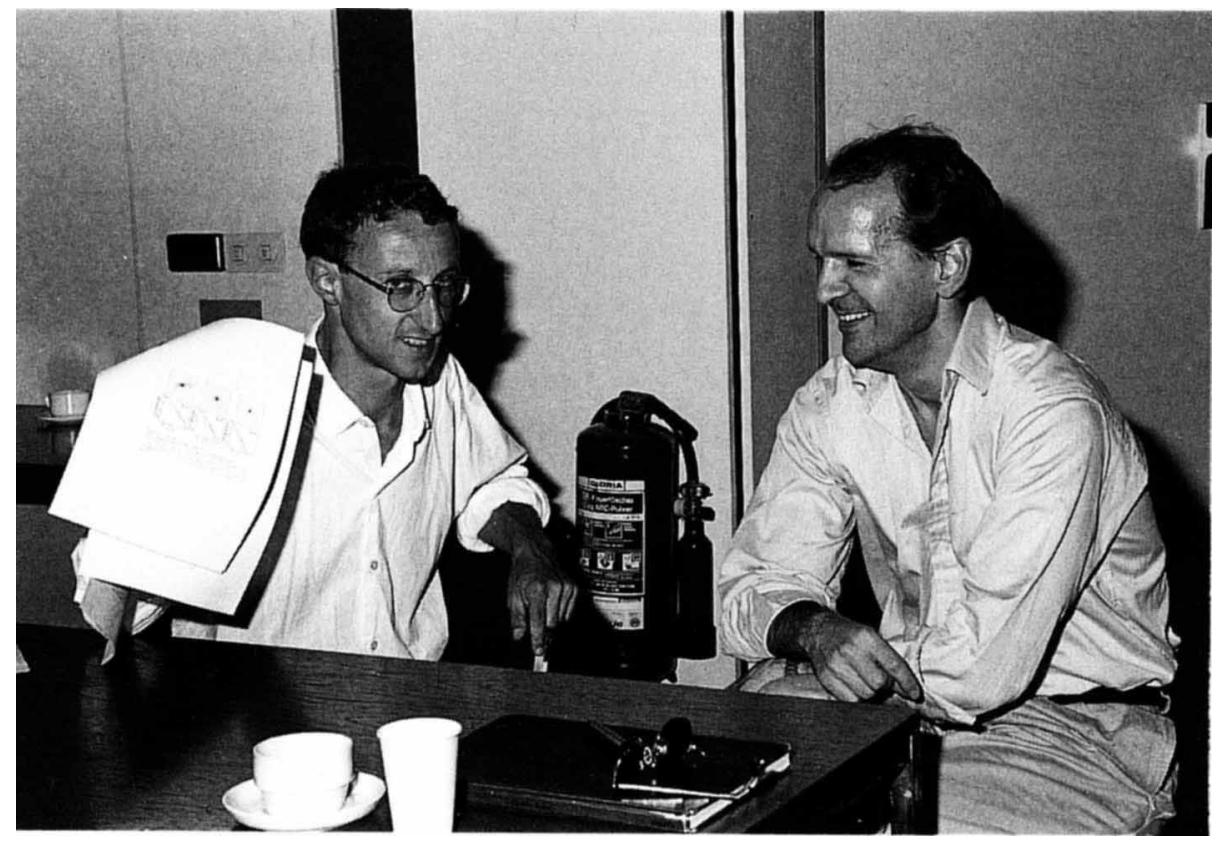

Mark Dickinson and Steve Warren

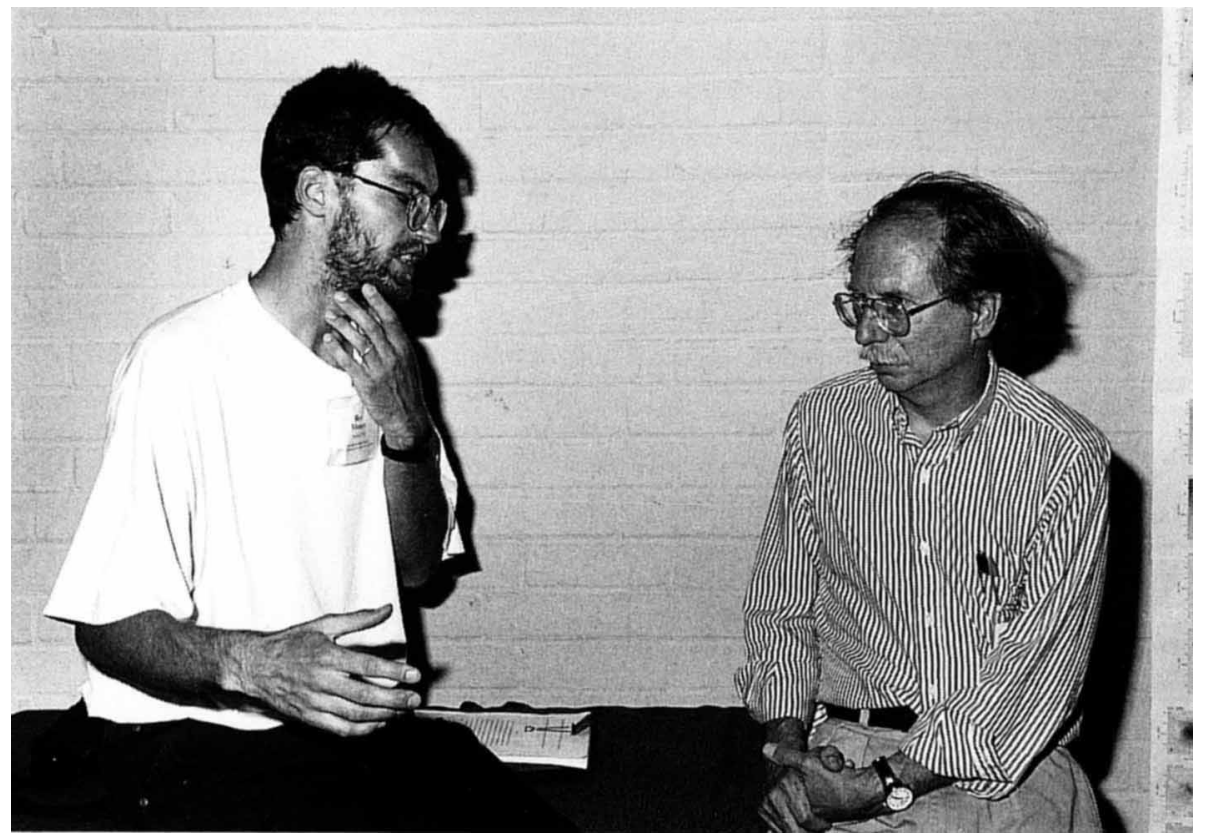

Ben Moore and Gus Oemleı 


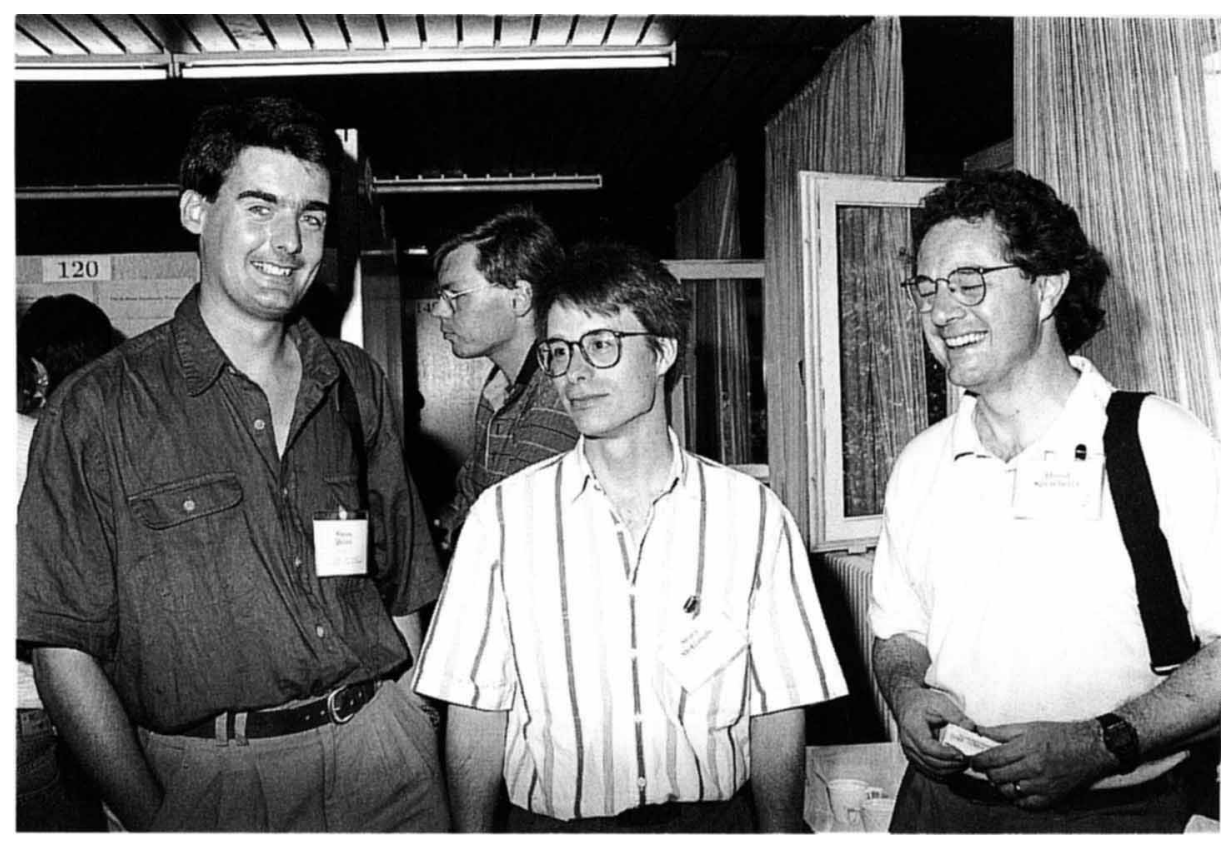

Simon Driver, Stacy McGaugh and David Sprayberry

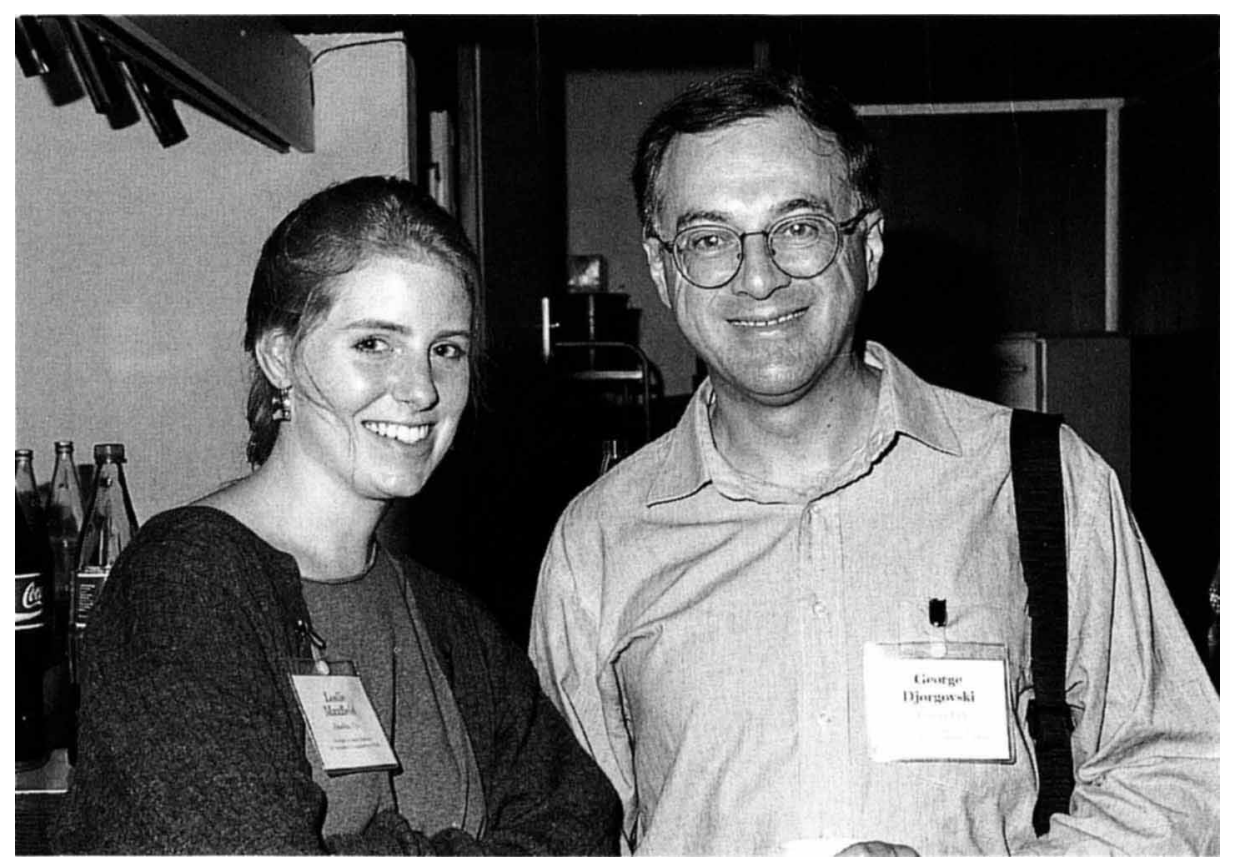

Leslie Maxfield and George Djorgovski 


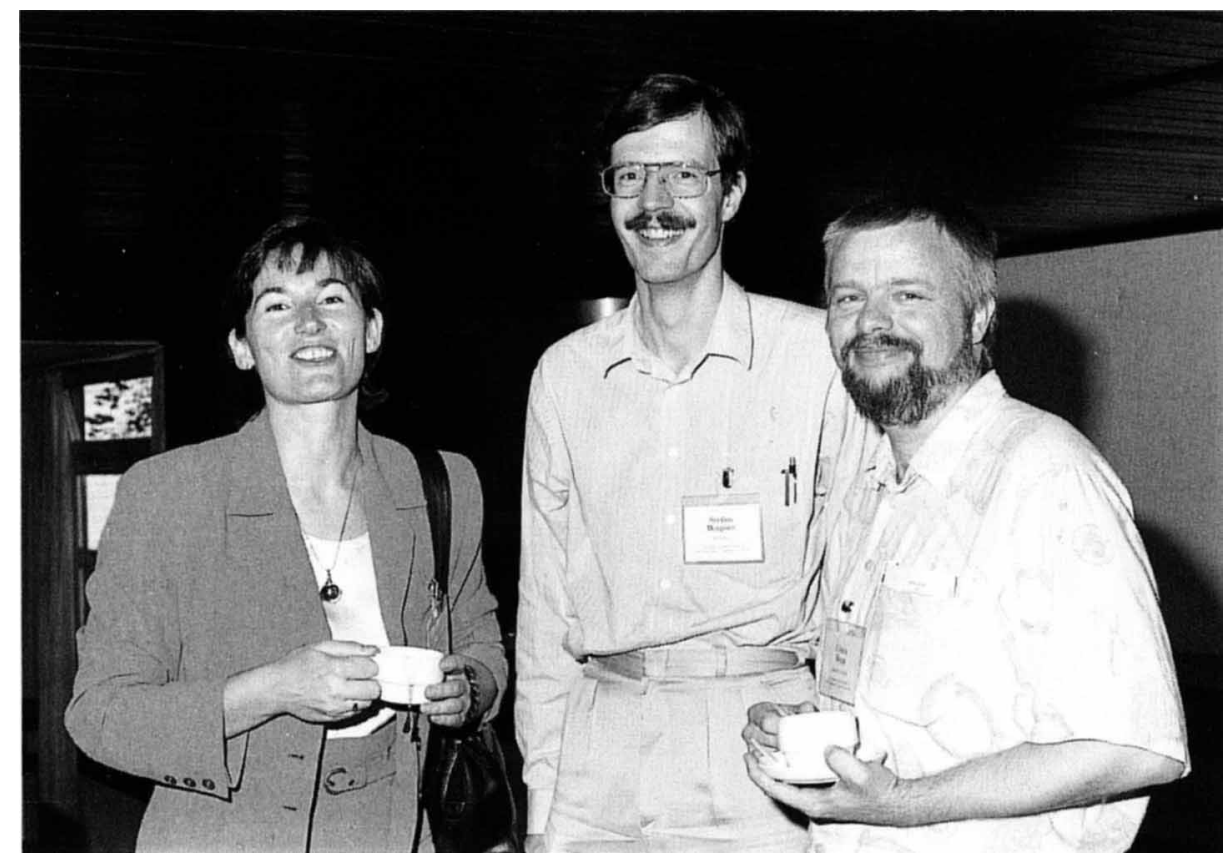

Regina Schulte-Ladbeck, Stefan Wagner and Ulrich Hopp

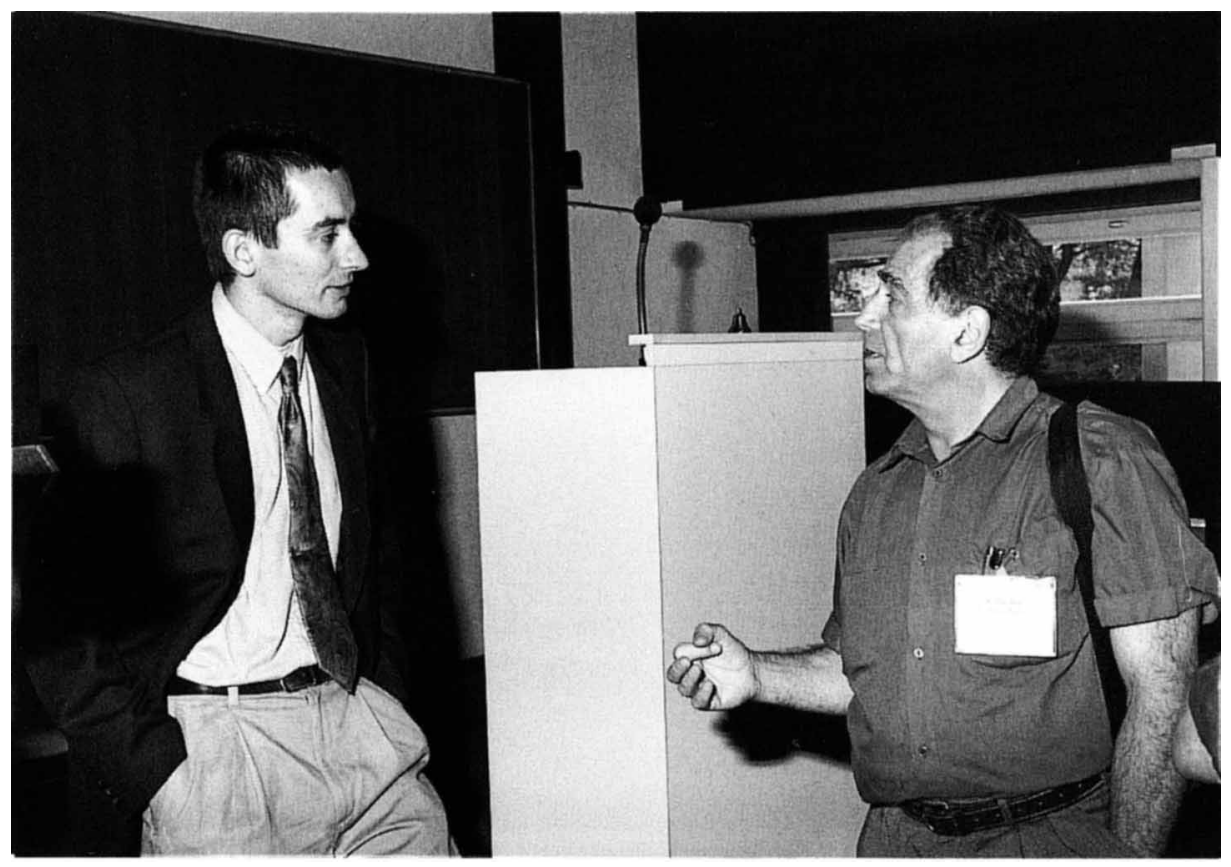

Roeland van der Marel and Ed Khachikian 


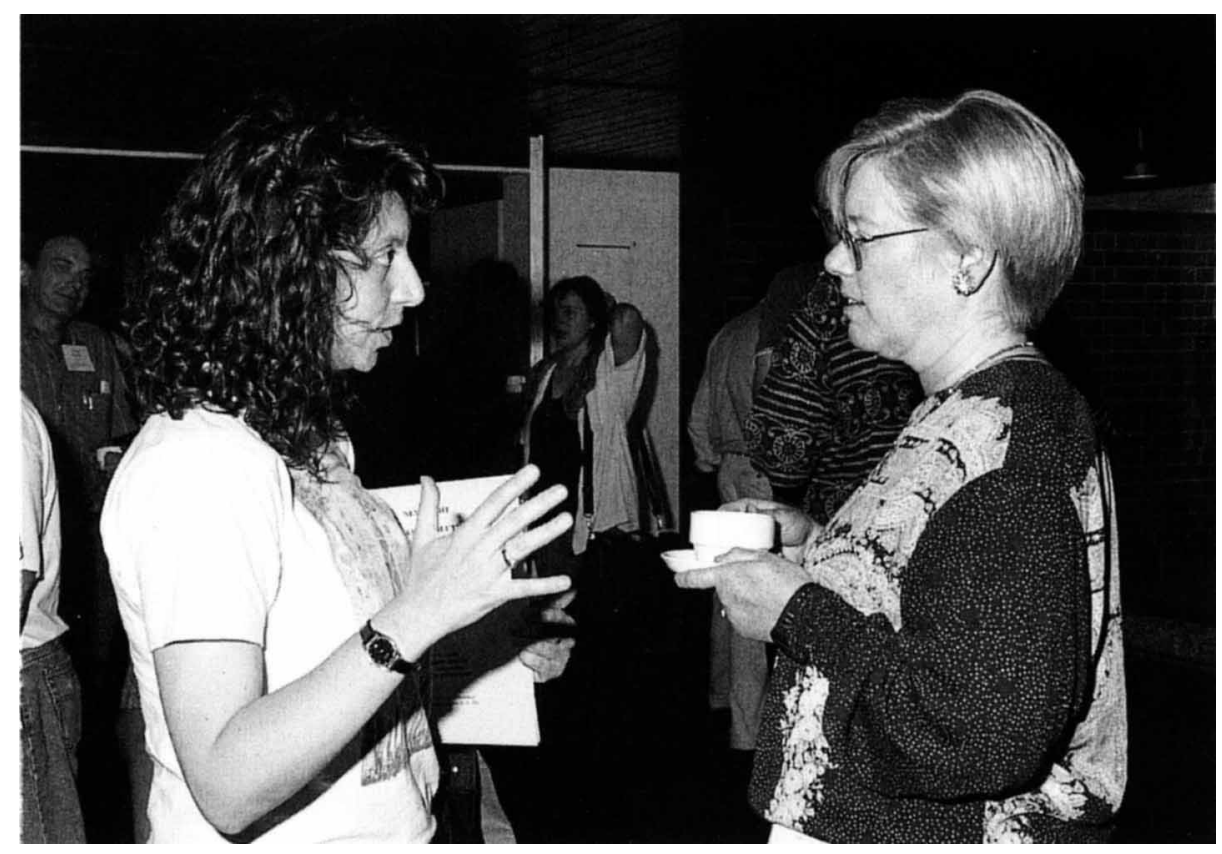

Paola Belloni and Sandy Faber

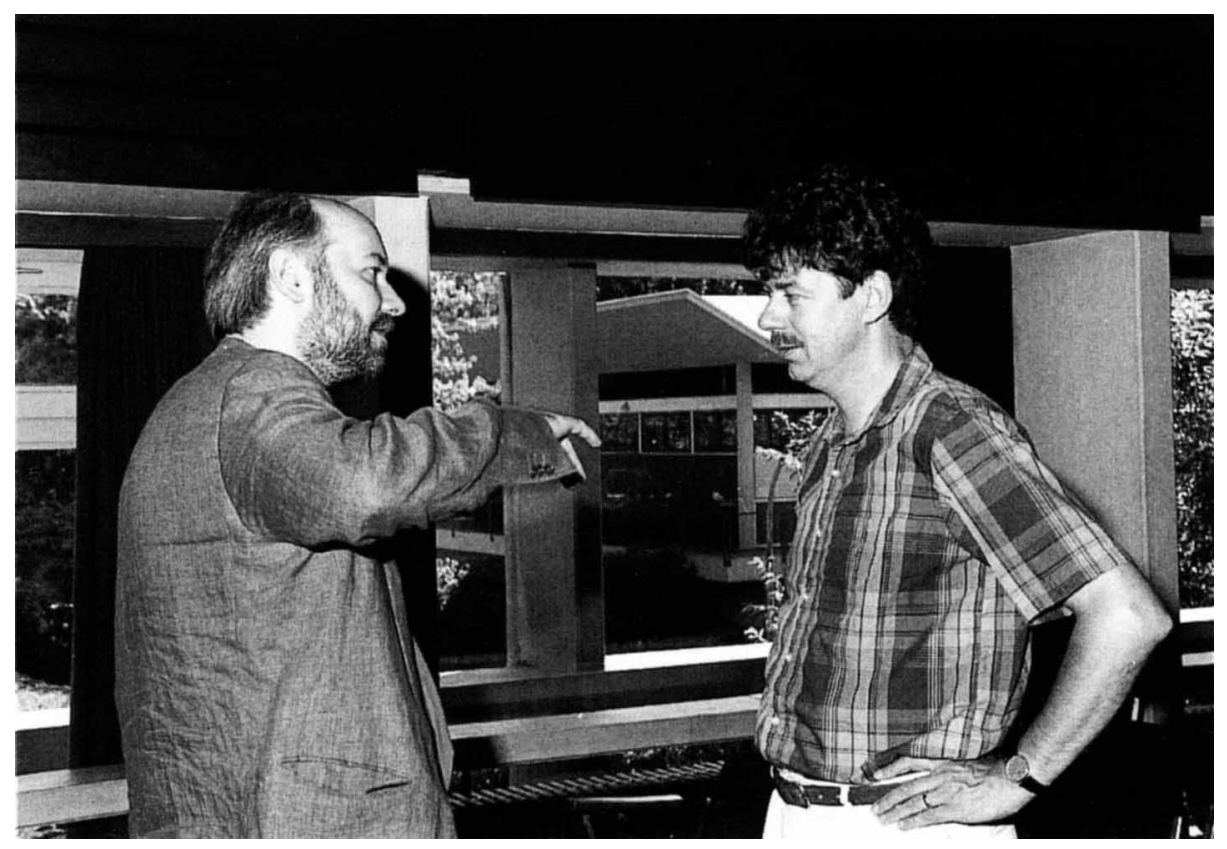

Ralf Bender and Simon White 


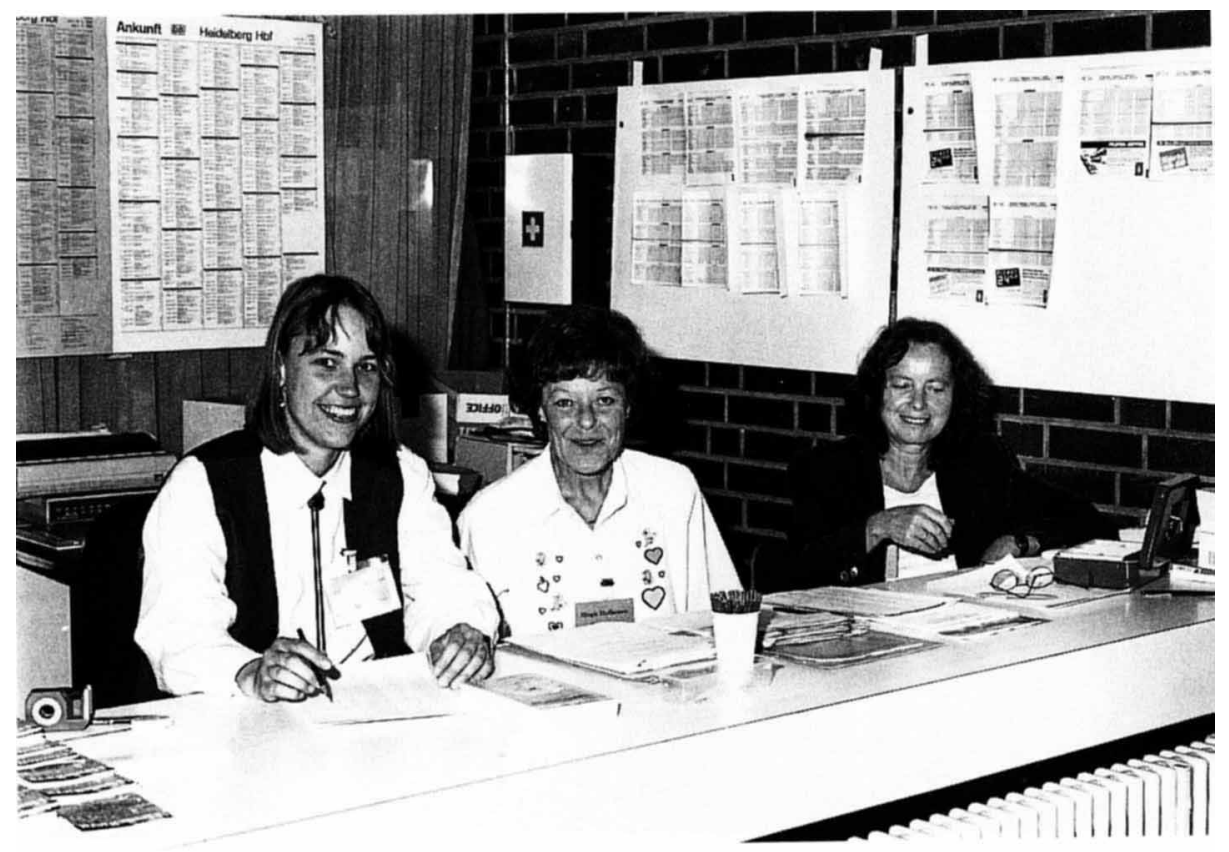

Gaby Ramge, Birgit Hoffmann, Elke Bär from the LOC

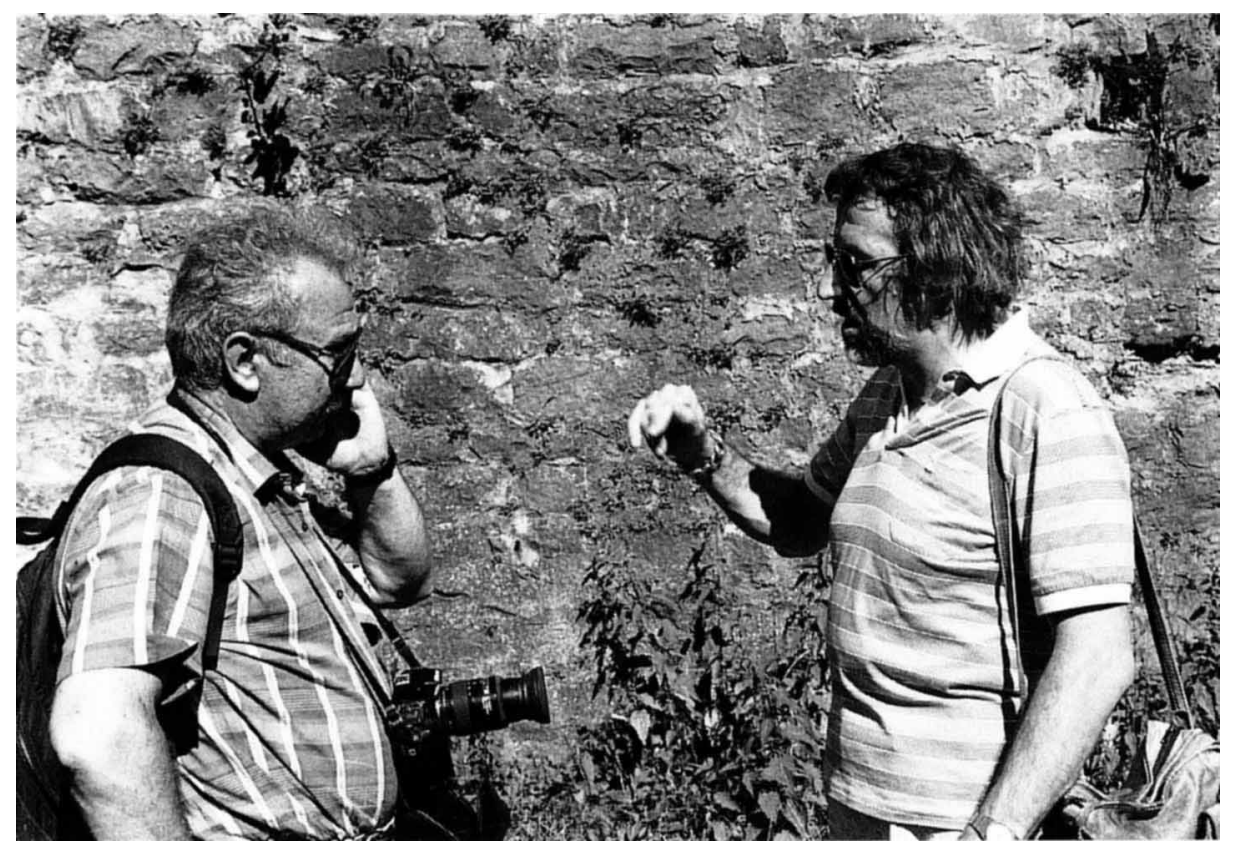

Cesare Chiosi and Claus Möllenhoff 


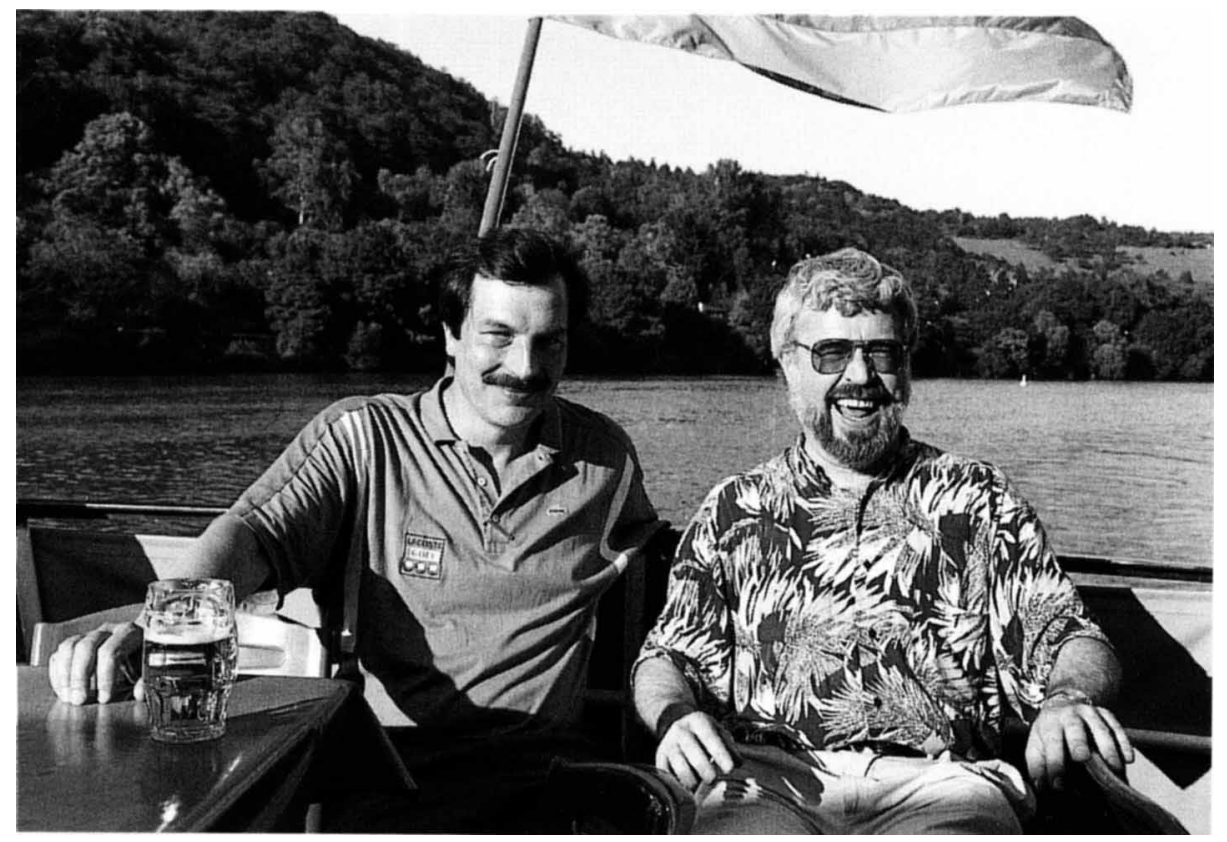

Michael Rosa and Joachim Krautter

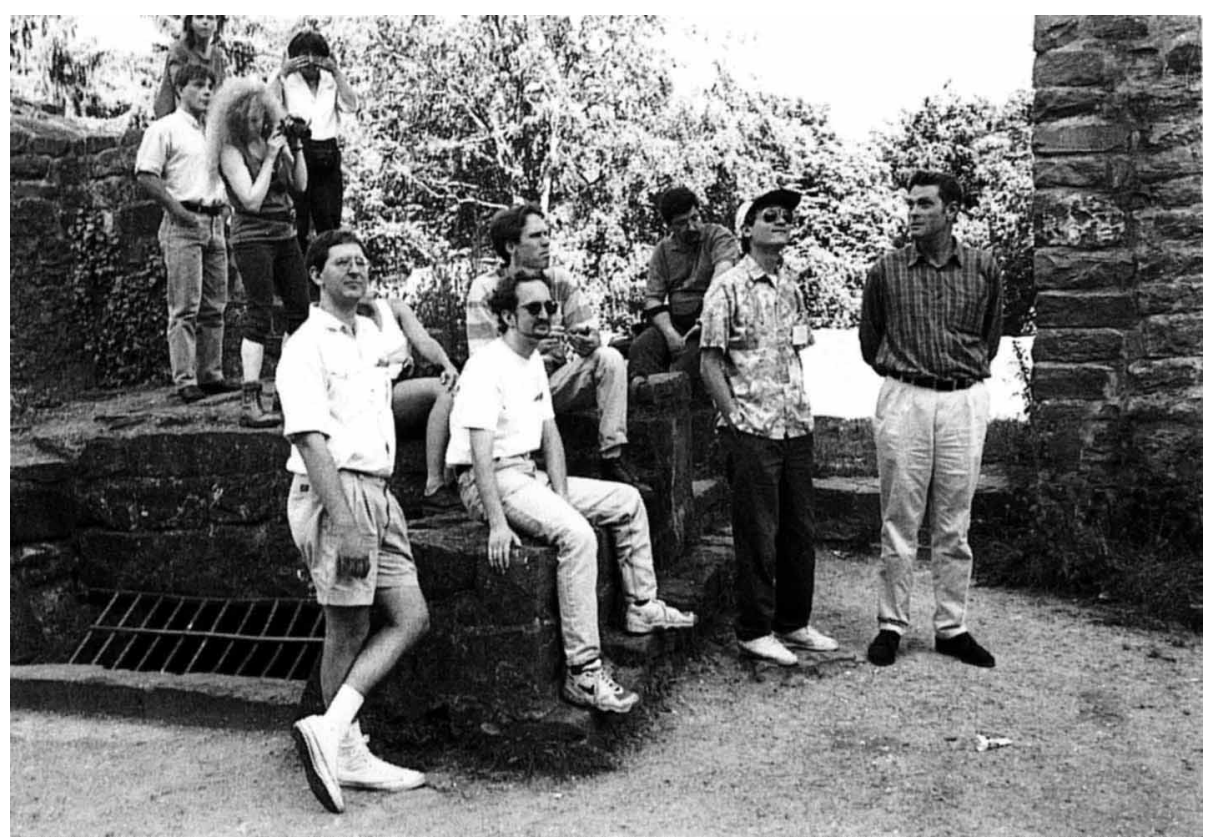

In the castle 




Pascale Jablonka, Javier Gorgas and Ben Dorman

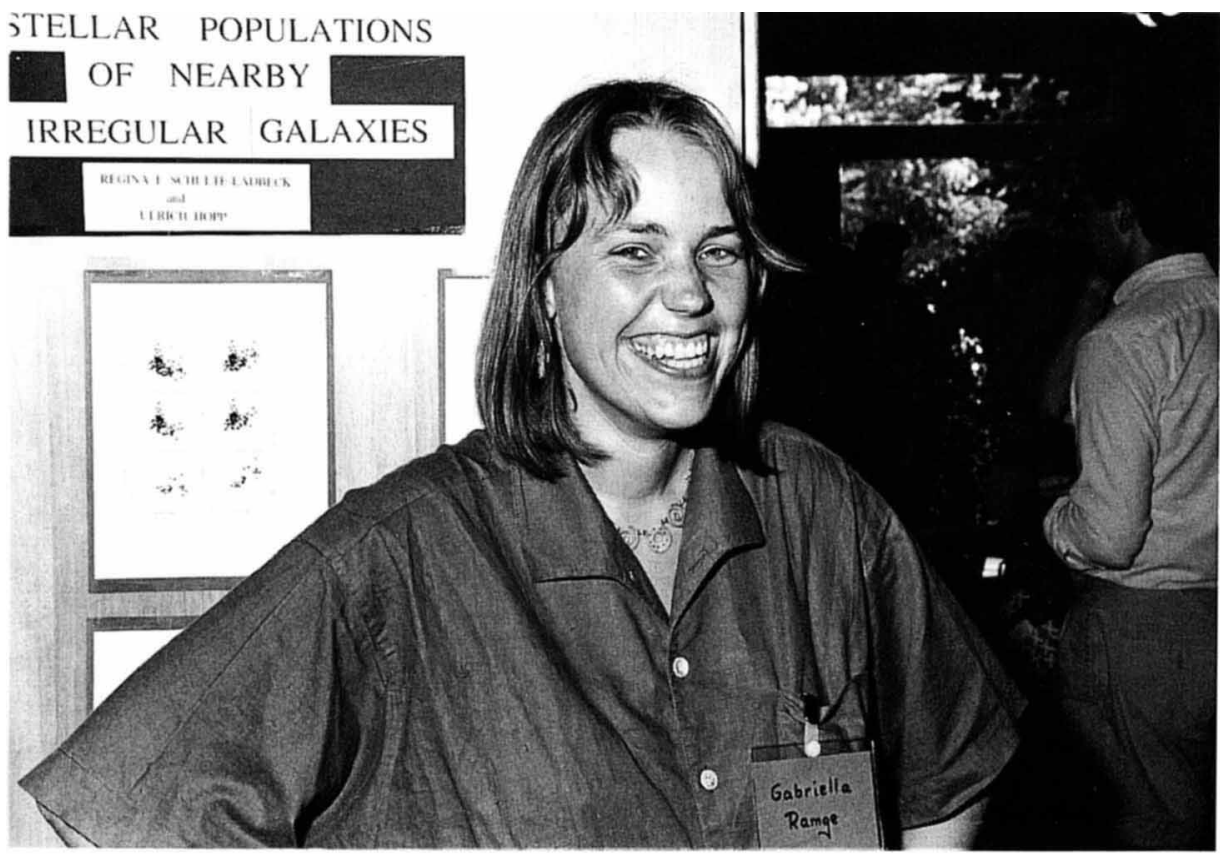

Gaby Ramge who took all the pictures except this one 